\title{
Assessment of a Non-Optical Water Quality Property Using Space-Based Imagery in Egyptian Coastal Lake
}

\author{
Hala O. Abayazid, Ahmed El-Adawy \\ Coastal Research Institute, National Water Research Center, Ministry of Water Resources and Irrigation, Alexandria, Egypt \\ Email: halazid@yahoo.com
}

How to cite this paper: Abayazid, H.O. and El-Adawy, A. (2019) Assessment of a Non-Optical Water Quality Property Using Space-Based Imagery in Egyptian Coastal Lake. Journal of Water Resource and Protection, 11, 713-727.

https://doi.org/10.4236/jwarp.2019.116042

Received: April 30, 2019

Accepted: June 15, 2019

Published: June 18, 2019

Copyright $\odot 2019$ by author(s) and Scientific Research Publishing Inc. This work is licensed under the Creative Commons Attribution International License (CC BY 4.0).

http://creativecommons.org/licenses/by/4.0/

\begin{abstract}
Progressively anthropogenic intrusion and increasing water demand necessitate frequent water quality monitoring for sustainability management. Unlike laborious, time consuming field-based measurements, remote sensing-based water quality retrieval proved promising to overcome difficulties with temporal and spatial coverage. However, remotely estimated water quality parameters are mostly related to visibility characteristic and optically active property of water. This study presents results of an investigated approach to derive oxygen-related water quality parameter, namely Dissolved Oxygen (DO), in a shallow inland water body from satellite imagery. The approach deduces DO levels based on interrelated optical properties that dictate oxygen consumption and release in waters. Comparative analysis of multiple regression algorithms was carried out, using various combinations of parameters; namely, Turbidity, Total Suspended Solids (TSS), Chlorophyll-a, and Temperature. To cover the wide range of conditions that is experienced by Edku coastal lake, ground truth measurements covering the four seasons were used with corresponding satellite imageries. While results show successful statistically significant correlation in certain combinations considered, yet optimal results were concluded with Turbidity and natural logarithm of temperature. The algorithm model was developed with summer and fall data $\left(R^{2} 0.79\right)$, then validated with winter and spring data $\left(\mathrm{R}^{2} 0.67\right)$. Retrieved $\mathrm{DO}$ concentrations highlighted the variability in pollution degree and zonation nature within that coastal lake, as related to boundary interactions and irregularity in flow dynamics within. The approach presented in this study encourages expanded applications with space-based earth observation products for exploring non-detectable water quality parameters that are interlinked with optically active properties in water.
\end{abstract}




\section{Keywords}

Remote Sensing, Algorithm Model, Coastal Lake, Dissolved Oxygen

\section{Introduction}

Increasing demands and progressive development process have compromised sustainability potential of the coastal lakes in Egypt. The quality of water resources dictates beneficial uses offered as well as functionality of the aquatic ecosystem, especially with the alarming pollution level associated with the anthropogenic activities. Thus, continuous monitoring and frequent update of water resources status are required for sound management planning and corrective measure scenarios. However, such tasks require comprehensive data collection with adequate temporal and spatial coverage. Remote sensing is an advancing field that has the potential in reducing field work difficulties, and increasingly considered an essential planning tool.

\subsection{Remote Sensing-Based Water Quality Retrieval}

Several studies in literature have addressed retrieval of water quality parameters using remote sensing techniques. Significant correlations have been found between specific water quality parameters and reflectance measured with satellite sensors. These parameters cause change to the spectral properties of reflected light and, hence, are remotely detectable [1]. Recent research by Swain and Sahoo (2017) argued that certain conservative pollutants can be distinctively detected with different reflectances received in the electromagnetic spectrum because no biochemical reactions or ionic exchange are experienced [2].

Retrieving properties such as water clarity; turbidity, and Total Suspended Solids (TSS) concentrations using earth observation imageries have been tackled in applied research studies worldwide (e.g. [3]-[10]). In 2008, He et al. presented water quality retrieval models with proven successful results for optical nitrogenous and phosphorous components [6]. Other parameters such as chlorophyll-a (chl-a) and Colored Dissolved Organic Matter (CDOM)) have also been covered in various studies (e.g. [8] [11] [12] and [13]).

Remotely deriving weak and/or non-optical water quality characteristics that have no directly-detectable reflection, is challenging. Consequently, early studies are mostly focused on water physical and biogeochemical components that are considered optically active [14]. However, limitation to water quality characteristics that are related to Inherent Optical Property (IOP) narrows down the parameters that can be assessed by remote sensing techniques.

The Dissolved Oxygen (DO) concentration is considered a crucial indicator of water system healthiness, and governs recovery capability [15]. Yet, being a non-optically active parameter, DO levels cannot be directly retrieved using remote sensing technique. This research study aims to present an approach to 
detect Dissolved Oxygen concentrations in an inland shallow coastal lake, using space-based imageries.

Based on grounds of early DO modeling theories, as well as regional conditions, the study investigates the potentiality of deducing DO levels from optically detectable water quality parameters that affect, and be affected by, Oxygen presences in water.

\subsection{Study Area}

With growing population and development activities, the Nile Delta of Egypt experience challenging conditions. Lake Edku is located within the active Northwestern coastal zone of the Delta, between longitudes $30^{\circ} 8^{\prime} \& 30^{\circ} 23^{\prime} \mathrm{E}$ and latitudes $31^{\circ} 10^{\prime} \& 31^{\circ} 18^{\prime} \mathrm{N}$ (Figure 1). The lake is characterized of having systematically shrinking free open water, altered ecosystem and deteriorating water quality state [16]. Edku Lake serves an active agri-urban basin, and bordered by dense aquaculture practices. Accordingly, the lake receives wastewaters with different pollution degree from fish farming therapeutic drugs, nutrient flux from agricultural drainage network (e.g. Edku, El-Boussili, Khairy and Bearsik drains), in

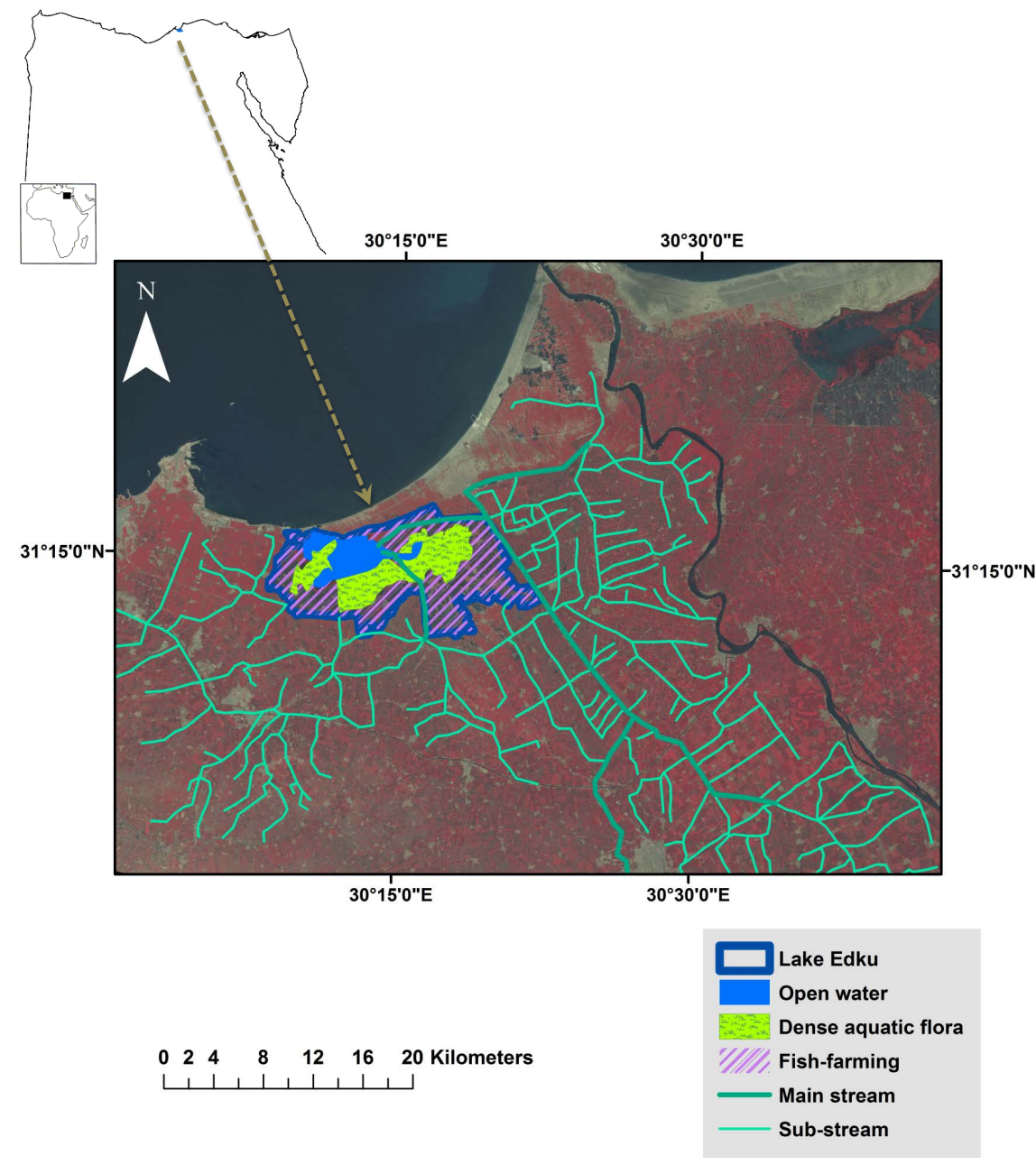

Figure 1. Edku Lake. 
addition to effluents from municipal WasteWater Treatment Plants (WWTPs) and industrial facilities [17]. The lake is connected to the Mediterranean Sea with single opening "Boghaz Al-Maadia", which allows temporal tidal inflows and localized saline water interaction. Discharges with heavy nutrient levels, as well as the deceased salinity inputs, have encouraged excessive unwanted aquatic vegetation. That, in turn, disturbed natural circulation; flow dynamic and sediment transport, and hence self -purification within the lake [18].

\section{Materials and Methods}

This section addresses the basis of DO modeling that dictated selection process to the parameters included in this study application. Also, the ground truth data and corresponding satellite imageries considered are presented, and then followed by the approach adopted for algorithm development.

\subsection{Theory: Grounds for DO Modeling}

Modeling of Dissolved Oxygen in water bodies has been initiated in 1925 by Streeter and Phelps through an application in the Ohio River of the United States of America [19]. Simulation studies were based on the fact that the rate at which DO fluctuates in waters reflect the rate of Oxygen demand and release. Their modified model set foundation of DO sinks and sources through inclusion of factors proved affecting the Dissolved Oxygen depletion and recovery in a water body. Beside the initially considered coefficients that represent reaeration as well as settling/decay processes, the model extension added representative components of aquatic flora role in the Oxygen production and exhaustion with photosynthetic activity. Furthermore, sediment consumption of DO has been added as an effective factor to be employed in the modified model for DO prediction. Equation (1) and Equation (2) state the early model and modefied version; respectively. More details can be found in the text book of Chapra (1997) [19].

$$
D_{t(\text { initial })}=D_{o} \exp \left(-K_{a} t\right)+\left[\frac{K_{d} L_{o}}{K_{a}-K_{c}} \times\left\{\exp \left(-K_{c} t\right)-\exp \left(-K_{a} t\right)\right\}\right]
$$

where; $D_{t}$ is the predicted dissolved oxygen deficit concentration, $t$ is the travel time, $L$ is the BOD level at point of interest, $L_{o}$ is the ultimate BOD level, $K_{a}$ is the reaeration rate, $K_{d}$ is the decomposition rate, $K_{s}$ is the settling removal rate, $K_{c}$ is the CBOD decay coefficient, and $D_{o}$ is the initial value of the oxygen deficit.

$$
\begin{aligned}
D_{t}= & \frac{K_{c} L_{o}\left(\mathrm{e}^{-K_{c} t}-\mathrm{e}^{-K_{a} t}\right)}{K_{a}-K_{c}}+\frac{K_{n} N_{o}\left(\mathrm{e}^{-K_{n} t}-\mathrm{e}^{-K_{a}}\right)}{K_{a}-K_{n}}-\frac{P\left(1-\mathrm{e}^{-K_{a} t}\right)}{K_{a}}+\frac{R\left(1-\mathrm{e}^{-K_{a} t}\right)}{K_{a}}+ \\
& \frac{S_{b}\left(1-\mathrm{e}^{-K_{a} t}\right)}{K_{a}}+D_{o} \mathrm{e}^{-K_{a} t}
\end{aligned}
$$

The modified model, represented in Equation (2), has added factors as; $P$ the photosynthetic oxygen production rate, $\mathrm{R}$ the algal respiration rate, $S_{b}$ the sediment oxygen demand rate, $N_{o}$ the initial Nitrogenous BOD (NBOD), and $K_{n}$ the 
NBOD decay coefficient.

\subsection{Field Measurements}

Ground truth data used were obtained from published research study by Okbah et al. (2017) [20]. Authors presented data collected in ten sampling locations distributed throughout the Edku Lake. Spatial distribution of field measurement locations reflects variability in the lake water quality, with regard to boundary interaction as well as flow movements within the lake (Figure 2). Further, sampling campaigns have been carried out during four seasons; spring, summer, fall and winter of year 2016, which reflected the variable conditions that the coastal lake experince. Statistics of the field measurements show that in summer time DO levels reach the lowest concentrations, ranging from 1.6 to $9.4 \mathrm{mg} / \mathrm{L}$, and experience wide variability within the lake with standard deviation of 3 among the ten investigated locations. Meanwhile, the highest DO levels occur in winter, ranging from 11.3 to $18.1 \mathrm{mg} / \mathrm{L}$, with standard deviation of 2.3 . The lake water DO range from 7.5 to $14.0 \mathrm{mg} / \mathrm{L}$ in spring, whereas the fall season has slightly less concentrations, ranging from 5.0 to $13.1 \mathrm{mg} / \mathrm{L}$. Maximum measured DO concentrations were mostly found in zones " $\mathrm{C}$ " and " $\mathrm{D}$ ", as illustrated in Figure 3. On the other hand, minimum levels occur in locations within the eastern zone "A", where most of direct wastewater discharges reach the lake water.

\subsection{Remote Sensing Data}

In 2013, Ganoe and DeYoung presented theoretical basis for DO retrieval with the use of air-borne Raman spectroscopy instead of ship-based technology that customary required direct contact with the waterbody [21]. Authors argued the advantages of air-based technique in measuring DO when compared to time

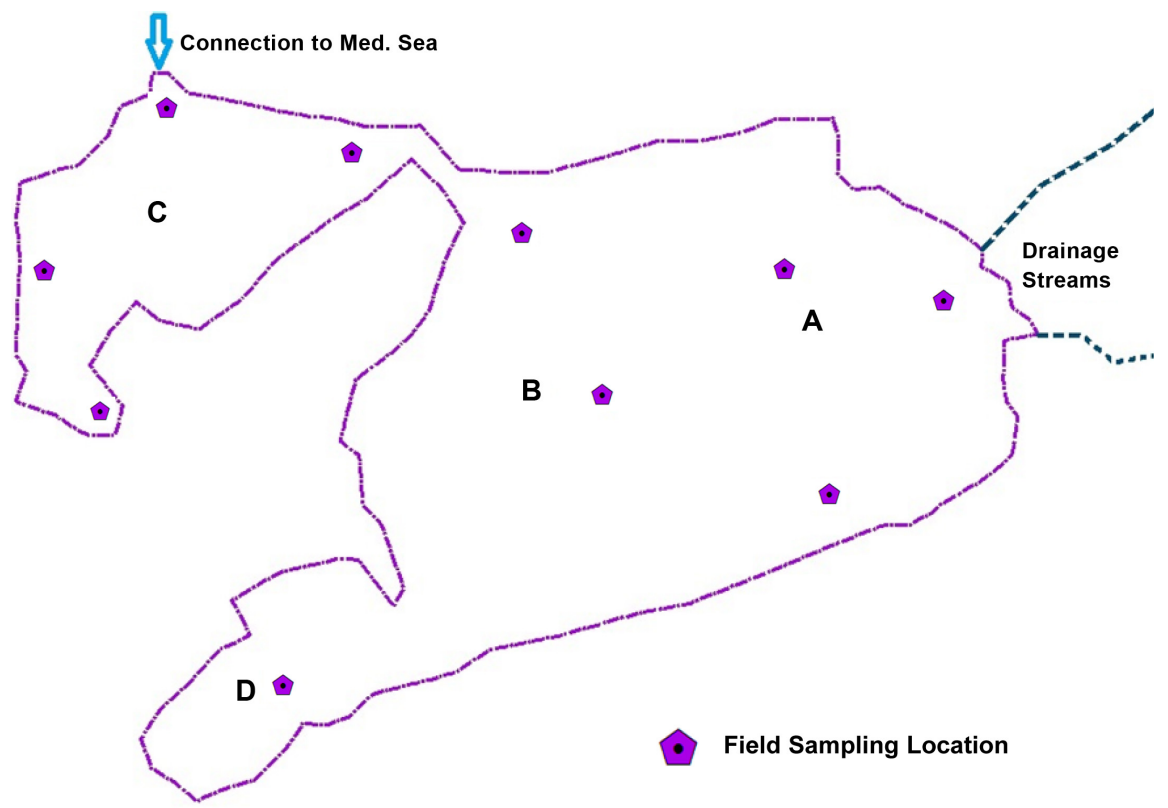

Figure 2. Field measurement locations in Lake Edku zones A, B, C, and D. 


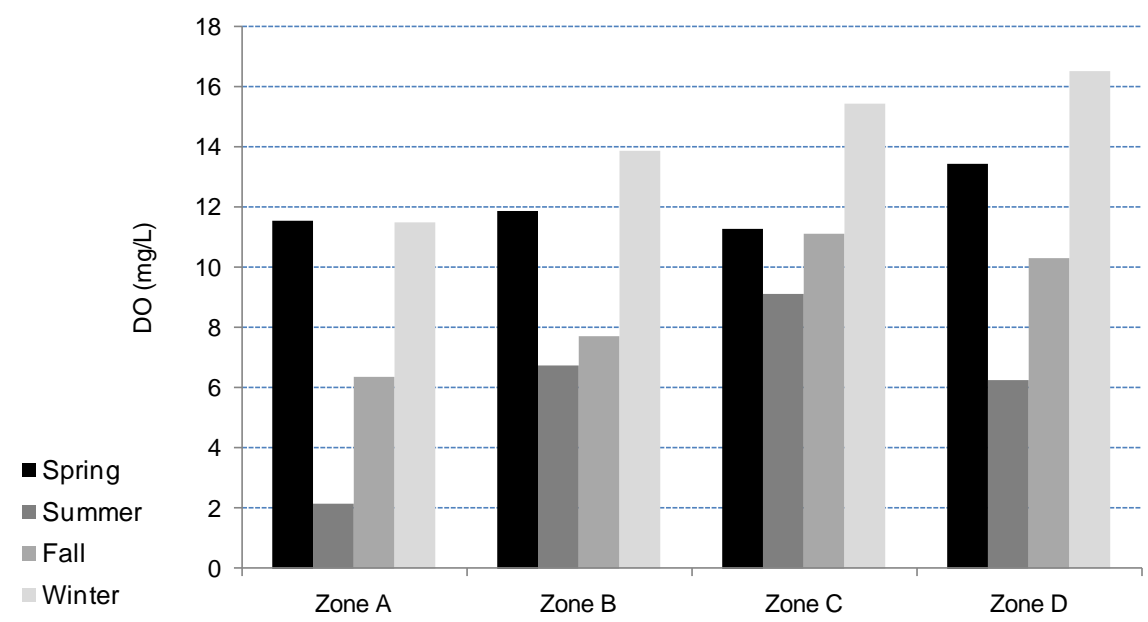

Figure 3. Observed DO data during four seasons in Lake Edku zones.

consuming as well as limitation in detecting variability in changing water conditions during field trips. The research concluded promising success of remote sensing retrieval of the temporal and spatial dynamics of dissolved gas distributions in coastal ecosystems. Yet aerial arrangements are costly and not always readily available, while space-borne sensors can have more frequent revisits and reasonably spatial coverage with advancing spectral resolution.

The imageries used in this study are the freely available Landsat 8 Operational Land Imager (OLI) from the United States Geological Survey (USGS) Earth-Explorer website. The Landsat 8 (OLI/TIRS) is the most recent satellite that was launched in 2013 under the Landsat program, with swath width of 170 $\mathrm{km}$ and 16 days' revisit interval. Since the in situ DO data have been collected during spring, summer, fall and winter of year 2016, images used in this study were acquired on nearest corresponding overpass dates to match the sampling data timing Table 1. Table 2 states the spectral range considered in this study, covering visible and Near-Infrared as well as Thermal Infrared bands. The necessary image processing and result analysis were carries out in Geographic Information System (GIS) environment.

\subsection{Algorithm Development}

Satellite imageries were processed for carrying out multiple regression technique and reaching best algoritm model for DO retrival in Lake Edku. Analysis has been performed with the spatially distributed field measurements of Dissolved Oxygen as related to the spectral reflectance values derived from Landsat images at corresponding dates in year 2016. The available field data were divided into two groups for building algorithm models. Then performance has been tested with the reserved second group of data for validation process.

Based on the previously mentioned grounds of Streeter and Phelps DO modeling, as well as regional conditions defining water quality in coastal lakes of Egypt, the trophic and sediment-related properties were considered key factors 
Table 1. Used Landsat 8 (OLI) scenes and dates of acquisition.

\begin{tabular}{cc}
\hline Scene ID (path177/row38) & Date Acquired \\
\hline "LC81770382016071LGN01" & $11-$ Mar-2016 \\
"LC81770382016151LGN01" & 30 -May-2016 \\
"LC81770382016231LGN01" & 18 -Aug-2016 \\
"LC81770382016343LGN01" & 8-Dec-2016 \\
\hline
\end{tabular}

Table 2. Landsat 8 (OLI) spectral bands considered in this study.

\begin{tabular}{cc}
\hline Landsat 8 (OLI) bands & Spectral range $(\mu \mathrm{m})$ \\
\hline Band 2 (Visible) & $0.450-0.51$ \\
Band 3 (Visible) & $0.53-0.59$ \\
Band 4 (Visible) & $0.64-0.67$ \\
Band 5 (Near-Infrared) & $0.85-0.88$ \\
Thermal Infrared Sensor (TIRS) & \\
Thermal Infrared (Band 10) & $10.6-11.19$ \\
Thermal Infrared (Band 11) & $11.5-12.51$ \\
\hline
\end{tabular}

in selection. Primary, the parameters included for developing DO derivative algorithms were Turbidity, Total Suspended Sediments (TSS), and Chlorophyll-a. Also, Temperature was added in the DO retrieval process as an important driver affecting Oxygen level in water, especially with the thermal anthropogenic releases and flow dynamic irregularity within Lake Edku. Cutomarily, DO concentration in water is inversely related to the temperature. Therefore, zonation of thermal property is expceted to have direct reflection on DO retrieved distribution. In process, alternate combinations of the considered parameters have been investigated for optimal model results.

Turbidity and TSS levels were deduced using findings of the recent research study of Abayazid and El-Gamal (2017) [10]. Authors concluded regional algorithm models for remotely sensed Turbidity and TSS in the Nile delta coastal zone, in terms of Landsat 8 's reflectance from spectral bands; Band $2_{\text {ref, }}$ Band $4_{\text {ref }}$ and Band $5_{\text {ref, }}$ as presented in Equations 3 and 4, respectively.

$$
\begin{gathered}
\operatorname{lnTURBIDITY}=-1.2247+\left[0.08112 \text { Band } 4_{\text {ref }}\right]+\left[2.944 \ln \left(\text { Band } 2_{\text {ref }} / \text { Band } 4_{\text {ref }}\right)\right] \\
\operatorname{lnTSS}=0.0496\left[3.325+13.222 \text { Band } 5_{\text {ref }}\right]^{3.2214}
\end{gathered}
$$

while literature applications showed various retrieval algorithms for Chlorophyll-a (e.g. [8] [22] [23]), best agreeable results for quantifying Chlorophyll-a in Lake Edku were found with the ratio between reflectance from spectral bands 2 and 4 of landsat 8 (Equation (5)).

$$
\text { Chlorophyll-a }=\text { Band } 2_{\text {ref } /} \text { Band } 4_{\text {ref }}
$$

Thermal spectral data have been converted to Temperature "T", using the conversion formula presented in Equation (6) [24] 


$$
T=\frac{K_{2}}{\ln \left(\frac{K_{1}}{L_{\lambda}}+1\right)}
$$

where $L_{\lambda}$ is the spectral radiance, and $K_{1}$ and $K_{2}$ are the thermal conversion constants found in Landsat imagery metadata files. Surface water temperature levels are calculated using averaged values of Thermal Infrared Bands (10) and (11).

Sensitivity analysis was performed to select best combination of the considered parameters, with different seasonal conditions experinced in the lake. Accordingly, the optimal DO retrieval algorithm model with best fitting predictions, as well as least data requirement and calculation efforts, has been selected for result demonstration.

\section{Results}

Many factors control the DO concentration within a waterbody; both sources and sinks (e.g. consumption by flora and aerobic organisms, oxidation of carbonaceous and nitrogenous material, decomposition of organic material, photosynthetic activity, degrading inorganic chemicals, re-aeration possibility as well as temperature, and dynamics in flow. Drainage water inflowing into Lake Edku from the interconnected stream networks reflect the expanding urban activities and industrial facilities, beside the intensive agricultural processes. In addition, the aquacultural practices add an extra polluting source.

\subsection{Remotely Sensed Input Parameters}

The four parameters initially considered as inputs for DO modeling have been spatially derived for spring, summer, fall and winter seasons of year 2016, with corresponding Landsat imageries. Example illustrations are found in Figures 4(a)-(d) for Temperature, Turbidity, TSS and Chlorophyll-a levels within Lake Edku, respectively.

\subsection{Sensitivity Analysis}

For developing satellite-based Dissolved Oxygen retrieval model, analysis has been carried out with various combinations of input parameters versus DO field measurements. The selected ground truth data is distributed throughout the lake zones. Furthermore, the data covers the four seasons so that a wide range of water quality levels experienced in the lake is considered in the developed model. Table 3 presents model predictive capacity and goodness of fitting while considering selective inputs as well as seasonal variations of DO presence in the lake waters.

Sensitivity degree with DO retrieval showed that TSS and Turbidity have similar effect in detecting Oxygen consumption in the waterbody under consideration. It was also found that the least influential factor is the Chlorophyll-a for the conditions experienced in the coastal lake under consideration. Minor change with least effect in predictive capacity of the developed algorithm occurs when adding Chlorophyll-a to the input parameters. 


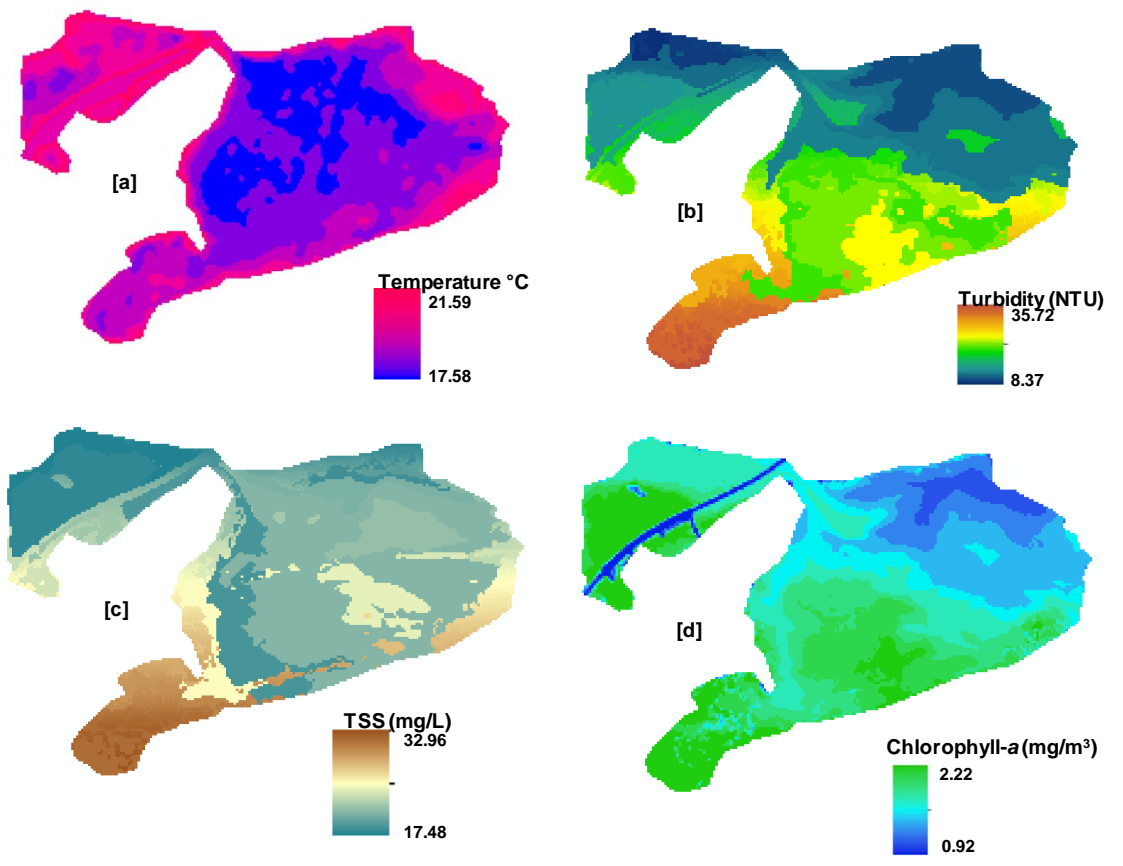

Figure 4. (a) Spatial distribution of derived water quality parameters within Lake Edku in spring, 2016: (a) Temperature $\left({ }^{\circ} \mathrm{C}\right)$; (b) Turbidity (NTU); (c) TSS (mg/L); (d) Chlorophyll-a $\left(\mathrm{mg} / \mathrm{m}^{3}\right)$.

Table 3. Sensitivity analysis for optimal DO retrieval algorithm model.

\begin{tabular}{ccc}
\hline Seasons & Input Parameters & Regression Coefficient $\left.\mathbf{R}^{2}\right)$ \\
\hline Spring \& Fall \& Winter & Turb, TSS, Chl, Ln-temp & 0.618 \\
Summer \& Fall \& Winter & Turb, TSS, Chl, Ln-temp & 0.630 \\
Spring \& Summer \& Fall & Turb, TSS, Chl, Ln-temp & 0.657 \\
Summer \& Fall & Turb, TSS, Chl, Ln-temp & 0.781 \\
Spring \& Fall & Turb, TSS, Chl, Ln-temp & 0.751 \\
Spring \& Winter & Turb, TSS, Chl, Ln-temp & 0.651 \\
Spring \& Summer \& Fall & Turb, TSS, Ln-temp & 0.613 \\
Summer \& Fall \& Winter & Turb, TSS, Ln-temp & 0.601 \\
Spring \& Fall \& Winter & Turb, TSS, Ln-temp & 0.584 \\
Spring \& Fall & Turb, TSS, Chl & 0.644 \\
Spring \& Fall & TSS, Chl, Ln-temp & 0.676 \\
Spring \& Winter & TSS, Chl, Ln-temp & 0.554 \\
Summer \& Fall & Turb, TSS, Ln-temp & 0.766 \\
Summer \& Fall & Turb, Chl, Ln-temp & 0.798 \\
Summer \& Fall & TSS, Ln-temp & 0.756 \\
Summer \& Fall & Turb, Ln-temp & $\underline{\mathbf{0 . 7 9 2}}$ \\
\hline
\end{tabular}

\subsection{Developed Algorithm Model for DO Retrieval}

Optimal derivative capacity for DO levels in Lake Edku, with least input parameter requirements, hence less processing works and costs, was found by using 
only Turbidity and natural logarithm of Temperature. The developed algorithm model, stated in Equation (7), proved reasonable fitness with regression coefficient of 0.79 (Figure 5).

$$
\mathrm{DO}=36.27+0.19(\text { Turb })-10.36 \ln (\text { Temp })
$$

The proposed algorithm was then applied to the second group of data reserved for testing, and satellite-based derived DO concentrations were compared with the corresponding field measurements. Validation results proved acceptable predictive capacity of the developed algorithm model, with $\mathrm{R}^{2}$ of 0.66 (Figure 6). Descriptive statistics for observed versus modeled yearly average DO levels within Lake Edku are presented in Table 4. The developed model shows highly agreeable predictions with field measurements. However, the model failed to represent the very low DO concentration occurrence in the lake during summer season, as found in Table 4.

Once validated, the developed model has been applied to a set of landsat imageris to obtain retrieved DO spatial distribution in Lake Edku in time steps. Figure 7 illustrates comparison for observed versus derived DO concentrations during four seasons in Lake Edku. For the purpose of demonstration, Figure 8

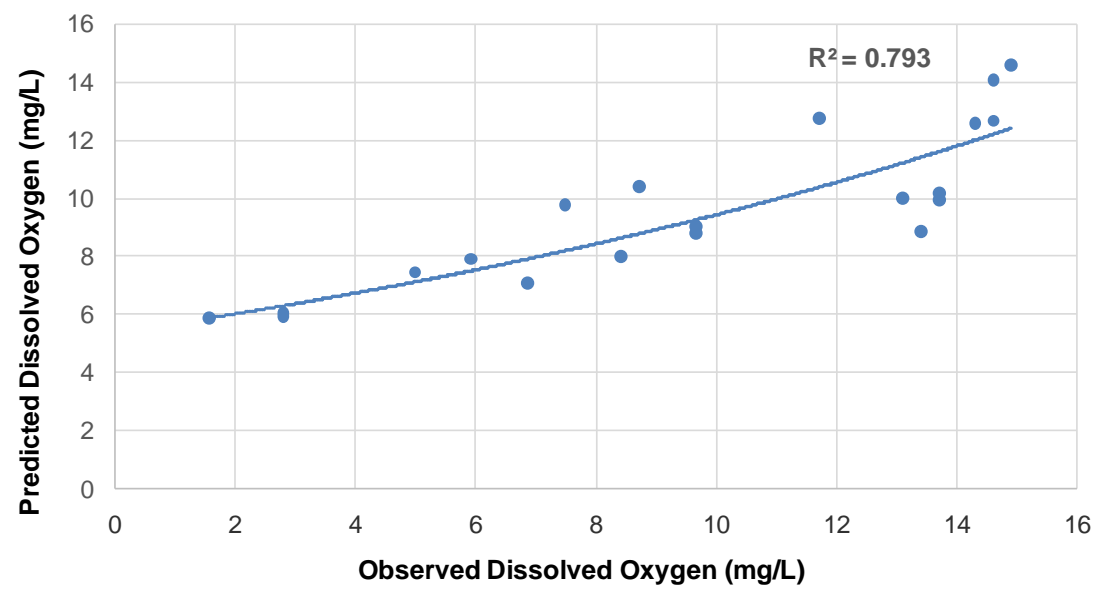

Figure 5. Predictive capacity of developed algorithm model for DO Satellite-based retrieval.

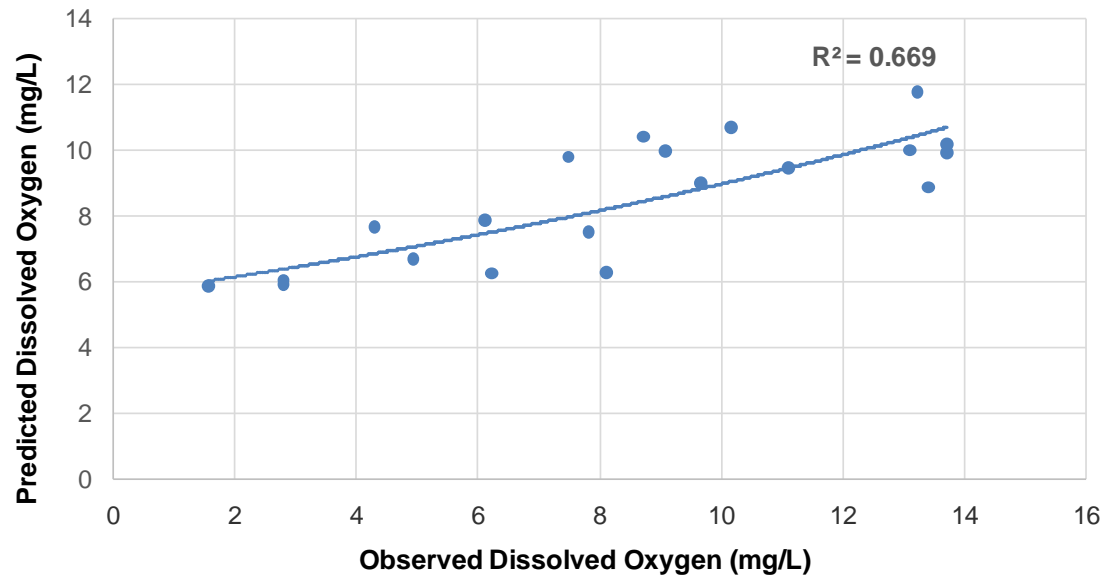

Figure 6. Validation of the developed model for DO retrieval. 
Table 4. Descriptive statistics for observed versus derived yearly DO levels within Lake Edku.

\begin{tabular}{ccc}
\hline \multirow{2}{*}{ Descriptive Statistics } & \multicolumn{2}{c}{ Do $(\mathrm{mg} / \mathrm{L})$} \\
\cline { 2 - 3 } & Observed & Modeled \\
\hline Mean & 10.440 & 9.064 \\
Minimum & 1.560 & 4.552 \\
Maximum & 18.107 & 20.271 \\
Standard Deviation & 4.042 & 3.841 \\
\hline
\end{tabular}

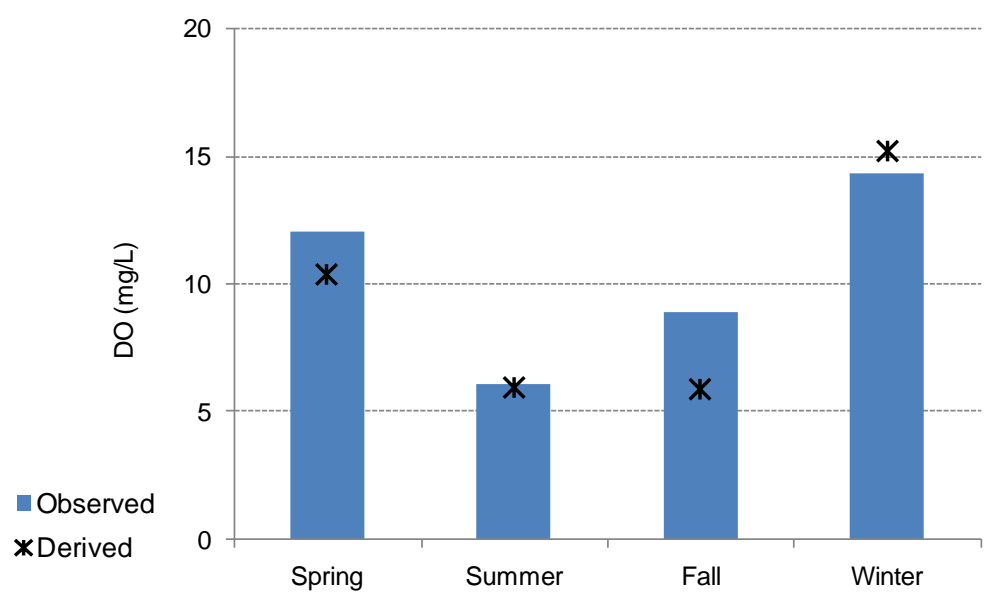

Figure 7. Observed versus derived DO concentrations during four seasons in Lake Edku.

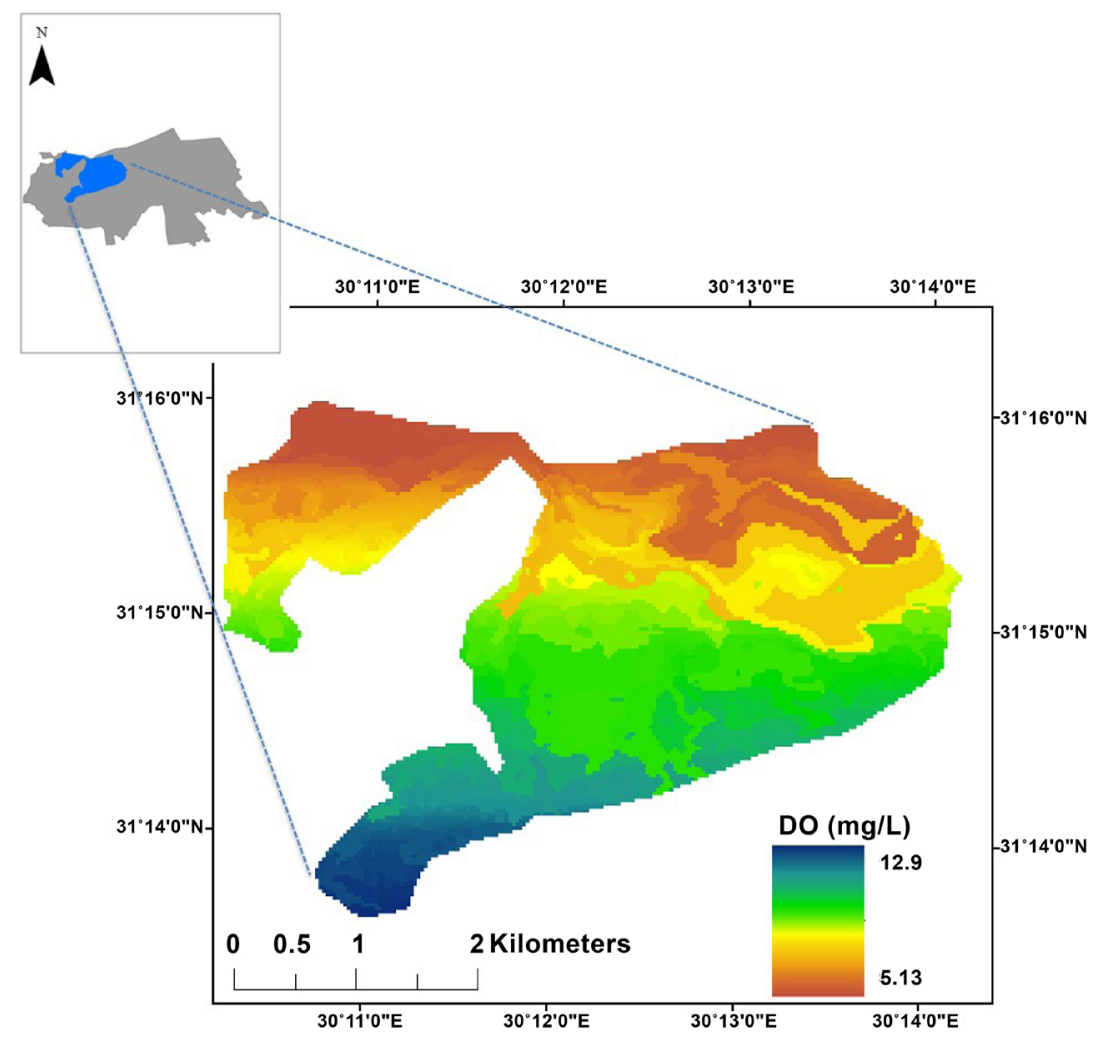

Figure 8. Retrieved DO concentrations in Lake Edku during winter season. 
shows an example mapping of DO concentrations throughout the lake zones in winter time.

\section{Discussion}

Main feature characterizes the Edku lake system is the patchy pattern of water quality. Dissolved Oxygen level ranges from less than $2 \mathrm{mg} / \mathrm{L}$, in extremely poor water conditions, to concentrations over $15 \mathrm{mg} / \mathrm{L}$. However, the exceedingly high DO level, with regional temperatures range of $15^{\circ} \mathrm{C}-30^{\circ} \mathrm{C}$ in coastal lakes, is considered $150 \%-250 \%$ supersaturation and potentially signifies an unhealthy eutrophication condition [25]. In investigating DO concentrations with reference to location within the lake, this case is clearly demonstrated in zone D of Lake Edku.

It has been noted that there are very high DO levels, detected both in field measurements as well as derived DO concentrations, in zone D which comprise entrapped waters with rare interaction. In reviewing this condition, it was found that the area experience intensive unwarranted aquatic flora growth, and accordingly high rate of the photosynthetic oxygen production, that coincides with less active hydrodynamics and water exchange.

On the other hand, Zone A, that is the nearest to major drainage inputs into the lake, has healthier DO concentrations. This zone, while loaded with excessive pollutants, experiences inflowing water velocity along with shallow water depth that allows partial compensation with higher re-aeration rate. Moderate range of DO concentrations exists mostly in zone $\mathrm{B}$, and zone $\mathrm{C}$, with combined effect of low temperature and suspended sediment concentrations as well as slower flow dynamics in zone B and localized tidal effect in zone $\mathrm{C}$.

\section{Conclusions}

Developments and consequent concerns about water resources beneficial capacity require continuous monitoring. Field-based assessment of quality state is usually faced by limitations in spatial coverage, frequency of sampling as well as possible economic and accessibility obstacles. Meanwhile, applications with remote sensing techniques have proved successful retrieval of water quality parameters, yet for optically active ones that have directly-detectable spectral signals.

This research study presents an approach for deriving a non-optically active property of water quality, Dissolved Oxygen (DO), with reference to other space-based retrievable parameters that affect and be affected by DO concentrations. Derivation methodology is based on the grounds of DO modeling, as well as regional conditions that define water quality in coastal lakes of Egypt. The selected ground truth data is distributed throughout the lake zones. Furthermore, the data covers the four seasons so that a wide range of water quality levels experienced in the lake is reflected in the developed model.

The study also presents results of sensitivity analysis for alternate input combinations. Consequently, optimal DO derivative algorithm model, with best pre- 
dictive capacity and least data requirement, was found. The developed optimal model comprises two satellite-based inputs, namely Turbidity and Temperature, for the Edku coastal lake. With the acceptable predictive capacity achieved, the validated model facilitates regular assessment, with more frequent DO mapping, and possible following of historical changes.

Spatial distribution of DO concentrations reflects the patchy pattern within Lake Edku, with regard to interactions in boundary as well as irregular flow dynamics within. The detected zonation nature calls for specific remedial measures that vary for each section.

Finally, remote sensing techniques proved to have the potential to play more roles in monitoring processes, and offer valuable information for sustainability management. The approach illustrated in this study sheds the light at the opportunity to expand applications with space-based earth observation products. The achieved promising results open the field for exploring more non-detectable water quality parameters that are interlinked with optically active properties in water. However, further applications with finer imageries and intensive ground truth data are recommended for the relationship with higher accuracy.

\section{Acknowledgements}

Authors acknowledge the generous opportunity offered by the United States Geological Survey (USGS) Earth-Explorer website, with freely available satellite imageries.

\section{Conflicts of Interest}

The authors declare no conflicts of interest regarding the publication of this paper.

\section{References}

[1] Gholizadeh, M.H., Melesse, A.M. and Reddi, L. (2016) A Comprehensive Review on Water Quality Parameters Estimation Using Remote Sensing Techniques. Sensors, 16, 1298. https://doi.org/10.3390/s16081298

[2] Swain, R. and Sahoo, B. (2017) Improving River Water Quality Monitoring Using Satellite Data Products and a Genetic Algorithm Processing Approach. Sustainability of Water Quality and Ecology, 9-10, 88-114. https://doi.org/10.1016/j.swaqe.2017.09.001

[3] Kloiber, S.M., Brezonik, P.L. and Bauer, M.E. (2002) Application of Landsat Imagery to Regional-Scale Assessments of Lake Clarity. Water Research, 36, 4330-4340. https://doi.org/10.1016/S0043-1354(02)00146-X

[4] Zhang, Y.Z., Pulliainen, J., Koponen, S. and Hallikainen, M. (2002) Application of an Empirical Neural Network to Surface Water Quality Estimation in the Gulf of Finland Using Combined Optical Data and Microwave Data. Remote Sensing of Environment, 81, 327-336. https://doi.org/10.1016/S0034-4257(02)00009-3

[5] Bilge, F., Yazici, B., Dogeroglu, T. and Ayday, C. (2003) Statistical Evaluation of Remotely Sensed Data for Water Quality Monitoring. International Journal of Remote Sensing, 24, 5317-5326. https://doi.org/10.1080/0143116031000156828 
[6] He, W., Chen, S., Liu, X. and Chen, J. (2008) Water Quality Monitoring in Slightly-Polluted Inland Water Body through Remote Sensing-A Case Study in Guanting Reservoir in Beijing, China. Frontiers of Environmental Science \& Engineering in China, 2, 163-171. https://doi.org/10.1007/s11783-008-0027-7

[7] Sravanthi, N., Ramana, I.V., YunusAli, P., Ashraf, M., Ali, M.M. and Narayana, A.C. (2013) An Algorithm for Estimating Suspended Sediment Concentrations in the Coastal Waters of India Using Remotely Sensed Reflectance and Its Application to Coastal Environments. International Journal of Environmental Research, 7, 841-850.

[8] Dona, C., Sánchez, J.M., Caselles, V., Domínguez, J.A. and Camacho, A. (2014) Empirical Relationships for Monitoring Water Quality of Lakes and Reservoirs through Multispectral Images. IEEE Journal of Selected Topics in Applied Earth Observations and Remote Sensing, 7, 1632-1641. https://doi.org/10.1109/JSTARS.2014.2301295

[9] Dorji, P. and Fearns, P.S. (2016) A Quantitative Comparison of Total Suspended Sediment Algorithms: A Case Study of the Last Decade for MODIS and Landsat-Based Sensors. Remote Sensing, 8, 810. https://doi.org/10.3390/rs8100810

[10] Abayazid, H. and El-Gamal, A. (2017) Employing Remote Sensing for Water Clarity Monitoring in the Nile Delta Coast. International Water Technology Journal, 7, 265-277.

[11] Brezonik, P., Menken, K.D. and Bauer, M. (2005) Landsat-Based Remote Sensing of Lake Water Quality Characteristics, Including Chlorophyll and Colored Dissolved Organic Matter (CDOM). Lake and Reservoir Management, 21, 373-382. https://doi.org/10.1080/07438140509354442

[12] Thiemann, S. and Kaufmann, H. (2000) Determination of Chlorophyll Content and Trophic State of Lakes Using Field Spectrometer and IRS-1C Satellite Data in the Mecklenburg Lake District-Germany. Remote Sensing of Environment, 73, 227-235. https://doi.org/10.1016/S0034-4257(00)00097-3

[13] Li, S., Wu, Q., Piao, X., Dai, Y. and Wang, X. (2002) Correlations between Reflectance Spectra and Contents of Chlorophyll-a in Chaohu Lake. Journal of Lake Sciences, 9, 228-234. https://doi.org/10.18307/2002.0306

[14] Giardino, C., Bresciani, M., Stroppiana, D., Oggioni, A. and Morabito, G. (2014) Optical Remote Sensing of Lakes: An Overview on Lake Maggiore. Journal of Limnology, 73, 201-214. https://doi.org/10.4081/jlimnol.2014.817

[15] United Nations Educational, Scientific and Cultural Organization (UNESCO) (2005) Water Resources Systems Planning and Management. 390-393.

[16] Abayazid, H. (2015) Assessment of Temporal and Spatial Alteration in Coastal lakes-Egypt. In: Proceedings of the 18th International Water Technology Conference, Sharm El Sheikh, 598-608.

[17] Siam, E. and Ghobrial, M. (2000) Pollution Influence on Bacterial Abundance and Chlorophyll-a Concentration: Case Study at Idku Lagoon, Egypt. Scientia Marina, 64, 1-8.

[18] Hossen, H. and Negm, A. (2017) Sustainability of Water Bodies of Edku Lake, Northwest of Nile Delta, Egypt: RS/GIS Approach. Procedia Engineering, 181, 404-411. https://doi.org/10.1016/j.proeng.2017.02.408

[19] Chapra, S.C. (1997) Surface Water Quality Modeling. McGraw-Hill Co., New York.

[20] Okbah, M., Abd El-Halim, A., Abu El-Regal, M. and Nassar, M. (2017) Water Quality Assessment of Lake Edku Using Physicochemical and Nutrients Salts, Egypt. 
Chemistry Research Journal, 2, 104-117.

[21] Ganoe, R. and DeYoung, R. (2013) Remote Sensing of Dissolved Oxygen and Nitrogen in Water Using Raman Spectroscopy. The NASA Scientific and Technical Information (STI), NASA Center for AeroSpace Information.

[22] Akbar, T., Hassan, Q. and Achari, G. (2010) A Remote Sensing Based Framework for Predicting Water Quality of Different Source Waters. The International Archives of the Photogrammetry, Remote Sensing and Spatial Information Sciences, 34, Part XXX.

[23] Brivio, P., Giardino, C. and Zilioli, E. (2001) Determination of Chlorophyll Concentration Changes in Lake Garda Using an Image-Based Reductive Transfer Code for Landsat TM Images. International Journal of Remote Sensing, 22, 487-502. https://doi.org/10.1080/014311601450059

[24] United States Geological Survey (USGS), Earth Resources Observation and Science (EROS) Center (2015) LANDSAT 8 (L8) Data Users' Handbook, Version 1.0, LSDS-1574.

[25] Environmental Protection Agency (1999) Guidance Manual for Compliance with the Interim Enhanced Surface Water Treatment Rule. Office of Water, United States Environmental Protection Agency. 